\title{
Effect of Computer Usage on Visual Reaction Time in Information Technology Professionals of Bangalore City
}

\author{
Sini Sreenivasan ${ }^{1}$, M.S. Kusumadevi ${ }^{2}$ \\ ${ }^{1}$ Post graduate, ${ }^{2}$ Professor, Department of Physiology, Bangalore Medical College and Research Institute, \\ Fort, KR Road, Bengaluru, Karnataka, India
}

\begin{abstract}
Background: Reaction time is the elapsed time between presentation of a sensory stimulus and the subsequent behavioural response. Time taken to respond to visual stimulus gives visual reaction time. In the modern world, the usage of computers for occupational purpose is increasing with increased duration of usage, especially in IT profession. Few studies have been done on reaction time in mobile phone users and video game players, but no study is done in occupational computer users.

Objective: To compare visual reaction time between occupational computer users (use computer for work $>40 \mathrm{hrs} /$ week) and the controls (recreational computer users : $<15 \mathrm{hrs} /$ week)

Materials and Method: Study was done on 30 occupational computer users (use computer for work $>40 \mathrm{hrs} /$ week) and 30 recreational computer users $(<15 \mathrm{hrs} /$ week) in the age group 20-35 years, after institutional ethical committee clearance and consent from all subjects. Visual Reaction Time was measured using Human Benchmark Software. Student's t test was used for statistical analysis and $\mathrm{p}$ value $<0.05$ taken statistically significant.
\end{abstract}

Results: Results showed a statistically significant decrease in visual reaction time in occupational computer users with a $p$ value of 0.01

Conclusion: Usage of computer for longer hours especially for occupational purpose decreases the visual reaction time in the individuals when compared with those who use it for lesser hours like recreational purpose.

Keyword: Visual reaction time, IT profession, Occupational computer users, Recreational computer users.

\section{Introduction}

Reaction time is the elapsed time between presentation of a sensory stimulus and the subsequent behavioural response ${ }^{1}$. Reaction time determines the alertness of a person ${ }^{2}$ and also represents the rate of processing of sensory stimulus by CNS and its execution in the form of motor response $\mathrm{e}^{3}$. There are three types of RT (1) Simple RT: Here there is one stimulus and one response. (2) Recognition RT: Here there is some

\section{Corresponding author}

\section{M.S. Kusumadevi}

Professor, Department of Physiology

Bangalore Medical College and Research Institute

Fort, K R Road, Bengaluru- 560002, Karnataka, India stimulus that should be responded to and other that should not get a response. (3) Choice RT: Here there are multiple stimulus and multiple responses. The concept of Reaction Time was first described by Abu Rayhan al-Biruni. Franciscus Cornelis Donders (1865), a Dutch Physiologist was the first to systematically measure human RT. He used a telegraph like device invented in 1840 by Charles Wheastone for his study ${ }^{4}$. Reaction time can be to visual stimulus or auditory stimulus. The time required to respond to a visual stimulus is known as Visual Reaction Time (VRT) and to an auditory stimulus is known as Auditory Reaction Time (ART) ${ }^{5}$.

In the modern world Computers have become an integral part of daily life ${ }^{6}$. Usage of computer can be for occupational purpose or recreational purpose. 
India has been in the forefront in cyber world with IT industry developing into a major service provider. It was estimated in the 1990's that 40-80 million Visual Display Terminals (VDTs) were there in the workplace. There are approximately six-computers/ 1000 population with an installation of 18 million Personal Computers (PCs) and their number increasing all the time ${ }^{7}$.

Computer use is an interactive activity involving psychomotor ability in using the computer mouse, to sensory and cognitive abilities such as speed of searching for icons, to issues with learning, memory and executive functions $s^{6}$. There are no studies done on visual reaction time in computer users. Many studies explored several cognitive domains in computer users. Some previous studies have shown that greater usage of computers can help in maintaining cognitive abilities.

\section{Objective}

To compare visual reaction time between occupational computer users (use computer for work $>40 \mathrm{hrs} /$ week) and the controls (recreational computer users: use computer for $<15 \mathrm{hrs} /$ week).

\section{Materials and Method}

This is a case-control study, done on 30 occupational computer users (use computer for work $>40 \mathrm{hrs} /$ week) ${ }^{8}$ and 30 recreational computer users (use computer for $<15 \mathrm{hrs} /$ week $)^{8}$ of either sex in the age group 20-35 years. The study was started after obtaining the ethical clearance from the institutional ethical committee. Occupational computer users were selected from different IT companies across the Bangalore city after considering the inclusion and exclusion criteria's and also age matched controls were selected.

A detailed history taking and relevant clinical examination was done for all subjects. Following which, subjects who had any medical/surgical illness, those having any visual disturbances, alcoholics and smokers were excluded. Also those who are involved in any sports or activities (like video games) which can improve VRT were excluded. Written informed consent was obtained from all subjects and each subject was explained about the whole procedure and objective of the study. Visual Reaction Time (VRT) was assessed using Human Benchmark Software9. This software consist of a red coloured screen on the laptop monitor. The subject is instructed to focus on the screen and when the red colour changes to green colour, he/she should press the enter key on the keyboard. Five trials were given and average time was taken as the visual reaction time. Lower the reaction time better is the subject's response to visual stimuli and also attention and fine motor skills are better in the subjects.

Data is presented as mean $\pm \mathrm{SD}$. Students $t$ test is used for comparing the visual reaction time between two groups with $p$ value of $<0.05$ as statistically significant.

\section{Results}

Table 1 shows demographic details of study group and control group

\begin{tabular}{|l|l|l|}
\hline Parameters & Study group & Control group \\
\hline Age (yrs.) & $25.36+0.73$ & $26.03+0.90$ \\
\hline Male & 17 & 14 \\
\hline Female & 13 & 16 \\
\hline
\end{tabular}

Table 2 shows VRT in study group and control group. The VRT in study group (which includes occupational computer users) is seen to be better than the VRT in control group (which includes recreational computer users) with a statistically significant $p$ value of 0.01 .

\begin{tabular}{|l|l|l|}
\hline Test & VRT & p value \\
\hline Study group & $385.93+13.82$ & \\
\hline Control group & $409.70+12.05$ & $0.01 *$ \\
\hline$* p$ value $<0.05$ statistically significant \\
\hline
\end{tabular}

\section{Discussion}

In the present study done on 30 occupational and 30 recreational computer users, the visual reaction time is seen to be better in those who use computer for occupational purpose ie., for longer duration. Lesser reaction time indicates faster response of the individuals to visual stimuli. Thus these individuals have a better sensory motor performance. The rate of processing of sensory stimulus by CNS and its response in the form of motor performances are faster in occupational computer users $^{1}$. 
There are no previous studies done on VRT in computer users. But few studies are done on cognition in computer users. These studies have proved an improvement in cognitive performances in computer users. The domains explored in those studies include attention, executive functions, learning \& memory etc. Patricia A Tun et al in 2010, found that frequent computer activity is associated with good cognitive function particularly executive control ${ }^{6}$. Slegers K et al in 2012 also reported similar findings. They used Visual Verbal Learning Test to measure verbal memory, LetterDigit Substitution Test to measure processing speed and Stroop Colour Word Test for selective attention and susceptibility to interference. They also found protective effects of the computer use for measures of selective attention and memory in both older ( $>50 \mathrm{yrs})$ and younger (24-49yrs) participants ${ }^{10}$. Another study done by Juno et al in 2017, found that the occupational computer users have better mental speed, sustained attention, response inhibition and visual memory compared to recreational computer users ${ }^{8}$. Johnson GM et.al, did a study on cognitive processing differences between frequent and infrequent internet users. Four modified cognitive assessment system subtests, each assessing one dimension of the PASS model of cognitive processing (ie., planning, attention, simultaneous and successive processing) were tested. The study showed that frequent internet users excelled in cognitive performances when compared with infrequent internet users ${ }^{11}$. There are few other studies done on mobile phone users and reaction time, which gives contrary results. In a study done by Chinmay Shah et al, VRT and ART were found to be prolonged with concomitant mobile use when compared to controls ${ }^{12}$.

Computer use requires continuous inputs from the users and therefore provides mental stimulation. Computer use is an interactive activity which requires visuomotor control like, visual-cognitive input (i.e., viewing a screen) and manual output (i.e., manipulation of peripheral devices such as a keyboard and mouse $)^{8}$. The continuous usage of computer thus increases their sensory motor performances and improvement in the visual reaction time.

\section{Conclusion}

Usage of computer for longer hours especially for occupational purpose decreases the visual reaction time in those individuals.
Acknowledgment: I am grateful to all the participants of the study for their kind cooperation.

\section{Conflict of Interest: Nil}

\section{Source of Funding: Self}

Ethical Clearance: Taken from Institutional Ethical Committee

\section{References}

1. Shelton J, Kumar GP. Comparison between Auditory and Visual Simple reaction time. Neuroscience \& Medicine. 2010;1:30-32.

2. Dube SP, Mungal SU, Kulkarni MB. Simple visual reaction time in Badminton players: A comparative study.National Journal of Physiology, Pharmacy \& Pharmacology.2015;5(1):18-20.

3. Solanki J, Joshi N, Shah C, Mehta HB, Gokhle PA. A study of correlation between auditory and visual reaction time in healthy adults. Int.J.Med.Public health. 2012;2(2):36-38.

4. Jain A, Bansal R, Kumar A, Singh KD. A comparative study of visual and auditory reaction times on the basis of gender and physical activity levels of medical first year students. International Journal of Applied and Basic Medical Research. 2015;5(2):124-27.

5. Bhabhor MK, Vidja K, Bhanderi P, Dodhia S, Kathrotia R, Joshi V. A comparative study of visual reaction time in table tennis players and healthy controls. Indian J.Physiol Pharmacol. 2013;57(4):439-442.

6. Tun PA, Lachman ME. The association between computer use and cognition across adulthood: use it so you won't lose it? Psychol Aging. 2010;25(3): 560-568.

7. Sharma AK, Khera S, Khandekar J. Computer related health problems among information technology professionals in Delhi. Indian $\mathrm{J}$ of Community Med.2006;31(1):36-38.

8. Cyril JM, Rajaram S. A comparative study of cognitive functions in Occupational \& recreational computer users. International Journal of Physiology. 2017;5(2):186-90.

9. Murray, M.M., Foxe, J.J., Higgins, B.A., Javitt, D.C., Shroeder, C.E. (2001). Visuo-spatial neural response interactions in early cortical processing during a simple reaction time task: a high-density 
electrical mapping study. Neuropsychologia, 39, 828-844.

10. Slegers K, van Boxtel MPJ, Jolles J. Computer use in older adults: Determinants and the relationship with cognitive change over a 6 year episode. Comput Human Behav. 2012;28(1):1-10.
11. Johnson GM. Cognitive processing differences between frequent and infrequent Internet users. Comput Human Behav. 2008;24(5):2094-2106.

12. Shah C, Gokhle PA, Mehta HB. Effect of Mobile Use on Reaction Time. Al Ameen J Med Sci (2010) 3(2):160-164. 